\title{
The Value of Vagueness: A Feminist Analysis
}

\author{
Ira Chadha-Sridhar
}

\section{Introduction}

Judicial verdicts matter. Apart from deciding the fate of litigants, common law verdicts hold precedential value. They create and alter legal cultures. Considering their importance, it is crucial to ask: what do judicial verdicts turn on? Each verdict is certainly influenced by the case facts, evidence and argumentation presented before the court. However, verdicts are also importantly shaped by how we think about language. ${ }^{1}$ Questions about language-about the relationship between words and meaning - are central to legal philosophy.

This paper discusses the philosophical problem of vagueness in language. ${ }^{2}$ The words used in legislation are often vague, leaving considerable room for discretion at the stage of judicial decision-making. Lawyers are told that this vagueness is a problem: it must be reduced or eliminated. This paper is an attempt to question this prevalent view against vagueness and conceptualise vagueness as a potential "feminist value". ${ }^{3}$ While vagueness's value has been discussed in other areas of legal theory, ${ }^{4}$ feminist philosophy can provide a new and important lens with which to approach this discussion.

In Section 1 of this paper, I will demonstrate the existence of an over-arching trend against vagueness at the stage of drafting statutes and during judicial interpretation. I refer to these dual stages throughout this paper to comprehensively understand vagueness and discuss its role in legal processes. Drawing from

I am grateful to have had the opportunity to present earlier versions of this paper at the Cambridge Legal Theory Discussion Group and the Young Scholar's Workshop 2020 at Humboldt University, Berlin. Thank you to Lars Vinx, Pritam Baruah and Shivprasad Swaminathan for helpful comments and to the anonymous referee at the CJLJ for their suggestions, and their belief, in this paper.

Ira Chadha-Sridhar, PhD Candidate, Faculty of Law, University of Cambridge, United Kingdom and Lecturer, OP Jindal Global University, Delhi (NCR) India. ic357@cam.ac.uk

1. See generally Andrei Marmor \& Scott Soames, eds, Philosophical Foundations of Language in the Law (Oxford University Press, 2011) and Peter M Tiersma \& Lawrence M Solan, eds, The Oxford Handbook of Language and Law (Oxford University Press, 2012).

2. For contemporary work on vagueness and law, see Hrafn Asgeirsson, The Nature and Value of Vagueness in the Law (Hart Publishing, 2020) and Timothy AO Endicott, Vagueness in Law (Oxford University Press, 2000).

3. I use this term to describe those set of values that are largely compatible with the project of feminist philosophy. The term value draws from the fact/value distinction that distinguishes the descriptive content of a fact from the normative force of a value. For discussions on the fact/ value distinction, see Irina Davydova \& Wes Sharrock, "The Rise and Fall of the Fact/Value Distinction" (2003) 51:3 The Sociological Review 357.

4. See Asgeirsson, supra note 2 and Timothy AO Endicott, "The Value of Vagueness" in Vijay K Bhatia et al, eds, Vagueness in Normative Texts (Peter Lang, 2005) at 27. 
philosophical literature on law in the analytic tradition, ${ }^{5}$ I will then show that the preference for precision over vagueness is rooted in our theoretical understandings and the concepts of law that we share and uphold.

Once I demonstrate this trend against vagueness, I proceed to examine the merit of this trend in Section 2. Is vagueness inevitable? Is it sometimes desirable? Through an exploration of these questions and a survey of contemporary work on law and language, I will demonstrate that vagueness is both inevitable and sometimes desirable in legal processes.

In Section 3, I turn to feminist philosophy to make a case for vagueness. Feminist philosophers have criticised the hierarchisation of universal, absolute knowledge in favour of situated forms of knowledge that centralise lived experiences. ${ }^{6}$ I argue that the linguistic tool of vagueness uniquely allows for lived experiences to be accommodated within legal processes. Thus, analysed from a feminist lens, vagueness can be of value.

If vagueness is of value and is sometimes desirable, it is important to outline when it is desirable and when it is not. I will do this in Section 4. It is not my aim, however, to provide an exhaustive list of doctrinal areas where vagueness is valuable in law. Instead, I restrict my claims to outlining two theoretical-doctrinal areas in which vagueness is certainly of value. I arrive at these areas by drawing from two distinct schools within feminist theory - 'the ethics of care' and 'the theory of intersectionality'. When legal systems deal with personal relationships between individuals (dealt with by care ethics) or power dynamics and discrimination (addressed through intersectionality), they must embrace vague terms in statutory language instead of resisting them. These areas of human life require particularity, subjectivity, and context to be centralised. Abstraction, both linguistic and legal, is ineffective.

This paper is therefore an attempt at conceptualising a feminist approach to the law-language question and the issue of vagueness. While vagueness's value has been the subject of much contemporary discussion in jurisprudence, a focussed feminist perspective to this debate is absent. By bringing in one such feminist perspective, I hope that this paper can contribute to arriving at a greater 'clarity about vagueness' and eventually help pave the way for greater socio-cultural transformation through law and legal systems.

5. I refer to texts in analytic jurisprudence here as the existing work on vagueness and law is largely located within this tradition. I proceed then to show that feminist philosophy can provide a new and interesting methodological lens with which to understand vagueness.

6. Marcel Stoetzler \& Nira Yuval-Davis, "Standpoint theory, situated knowledge and the situated imagination" (2002) 3:3 Feminist Theory 315 at 321. For a comprehensive discussion on feminist philosophy, see Ann Garry \& Marilyn Pearsall, eds, Women, Knowledge, and Reality: Explorations in Feminist Philosophy, 2d ed (Routledge, 2015) and Alison Stone, An Introduction to Feminist Philosophy (Polity Press, 2007). This epistemological commitment is shared by feminist philosophers across most orientations, including feminist analytic philosophers as noted in Noëlle McAfee, "Feminist Philosophy" in Edward N Zalta, ed, The Stanford Encyclopedia of Philosophy (2018) (Fall 2018 Edition), online at https://plato.stanford.edu/ archives/fall2018/entries/feminist-philosophy/. 


\section{Do Vague Words Make Bad Laws?}

The notion that laws must be as clear as possible is a fundamental tenet of legal systems. ${ }^{7}$ This notion is rarely ever questioned, and it is almost universally accepted. I will briefly outline the pervasiveness of this belief in legal drafting and policy in part 1 of this section. In part 2 and 3, I will explore the jurisprudential basis for this notion.

\section{A. The Need to Eliminate Vagueness}

The drafting of laws is an integral part of any legislative process. While the nuances of drafting vary across jurisdictions, certain trends apply almost universally irrespective of jurisdiction. The need to eliminate vagueness from statutory language is one such trend.

In the United Kingdom, the Drafting Guidance to the Office of the Parliamentary Counsel requires the use of precise and concrete words, as opposed to vague and abstract ones. ${ }^{8}$ Similarly, the Guide to Making Federal Acts and Regulations in Canada states that "perhaps the most important function of legislative drafting conventions is to reduce the ambiguity or vagueness of a natural language such as English or French". ${ }^{9}$ In a similar vein, the Legislative Department of the Indian government outlines their vision and mission through a list of goals that should be kept in mind when drafting all kinds of legislations. Of these goals, the goal of precision is given very high importance. ${ }^{10} \mathrm{~A}$ similar approach is taken in the United States of America, ${ }^{11}$ Australia ${ }^{12}$ and in parts of Europe. ${ }^{13}$

7. Lon L Fuller, The Morality of Law, revised ed (Yale University Press, 1969) at 63. Fuller states that clarity represents one of the most essential ingredients of legality.

8. Office of the Parliamentary Counsel, Drafting Guidance (United Kingdom, July 2018) 6 (Accessed 15 05, 2020) pdf online at assets.publishing.service.gov.uk/government/uploads/ system/uploads/attachment_data/file/727629/drafting_guidance_July_2018.2.pdf. While it is acknowledged here that sometimes vague words may be used, it is stated that "if a more precise word can be used, it is more likely to get the actual intention across." It is not the case that vague words cannot be replaced by more precise ones, but rather that they should not be so replaced. Precise alternatives to vague words almost always exist and thus will replace all vague words as per these instructions. This translates into a culture that prioritises precision in legislative drafting in the United Kingdom.

9. Government of Canada Privy Council Office, Guide to Making Federal Acts and Regulations: 2nd edition (2001), online at https://www.canada.ca/content/dam/pco-bcp/documents/pdfs/ fed-acts-eng.pdf [perma.cc/P3A9-YDCE].

10. "Vision Mission \& Objectives" (last modified 19 September 2017), online at Government of India Ministry of Law and Justice http://legislative.gov.in/about-us/vision-mission-andobjectives [perma.cc/625V-7E9W].

11. The United States has emphasised the 'plain language drafting approach' for the legislative and executive wings of their government. See the Plain Writing Act of 2010, Pub L No 111-274, 124 Stat 2861 (codified as amended at 5 USC 301) which defines plain writing as "writing that is clear, concise, well-organized, and follows other best practices appropriate to the subject or field and intended audience."

12. Australia has also emphasised the need to eliminate vagueness in its emphasis on plain English drafting. See Australian Government: Office of Parliamentary Counsel, Plain English Manual (2013), online at https://www.opc.gov.au/sites/default/files/plain_english_0.pdf [perma.cc/ F67H-4MVG].

13. The Interinstitutional Agreement on Common Guidelines for the Quality of Drafting of Community Legislation (1998) and the Joint Practical Guide on Drafting of Community 
This general trend against vagueness affects the way laws are drafted. For instance, drafters are often encouraged to eliminate vague words as they can be the source of frequent litigation. ${ }^{14}$ Examples of these vague words include certain commonly used phrases: "best efforts", "fair", "reasonable", "as it may deem fit" and other such phrases. ${ }^{15}$ Drafters are instructed to either replace these words with precise words ${ }^{16}$ or define these words in the definition sections of statutes with precise words. ${ }^{17}$ These instructions seek to increase objectivity in legal language at the stage of drafting and prevent any significant subjective deliberation at the adjudicatory stage.

These practices and drafting guidelines are supported by a range of academic texts across jurisdictions that encourage drafters to follow the maxim: precise words are always to be preferred over vague ones. ${ }^{18}$ In fact, this maxim is so intuitive that most of us rarely question it. The intuitive function of this maxim coupled with its universality shows that the maxim is entrenched in our understanding of law itself.

\section{B. The Desideratum of Clarity}

As we have seen, drafters are encouraged to eliminate vagueness to ensure that laws are as clear as possible. Interestingly, in most of the drafting guidelines referred to earlier, the words "clear" and "precise" are used synonymously. ${ }^{19}$ However, clarity and precision are distinct concepts. An understanding of this distinction is crucial to help understand our reservations, if any, against vague expressions.

The notion of clarity is perhaps best understood by referring to Lon Fuller's detailed discussion of this topic in his 1964 book, 'The Morality of Law'. ${ }^{20}$ In a lesser known part of this widely read book, Fuller makes important observations on clarity. If read closely, Fuller himself advances a subtle distinction between

Legislation in the European Union, stresses that Legislation should be clear, simple, precise and readily understandable by the public and economic operators. See Official Journal of the European Union 1999/C 73/01, Interinstitutional Agreement on common guidelines for the quality of drafting of Community legislation (22 December 1998), online at https:/eur-lex.europa.eu/ legal-content/EN/TXT/?uri=uriserv:OJ.C_.1999.073.01.0001.01.ENG\&toc=OJ:C:1999: 073:TOC [perma.cc/3QTM-73DG].

14. Arghya Sengupta \& Namrata Mukherjee, "Manual on Plain Language Drafting" (15 March 2017), online at Vidhi Centre for Legal Policy https://vidhilegalpolicy.in/research/manualon-plain-language-drafting/ [perma.cc/3VXK-EAFV].

15. Ibid at 42 .

16. Ibid at 42 .

17. Ibid at 42 .

18. See Esther Majambere, "Clarity, precision and unambiguity: aspects for effective legislative drafting" (2011) 37:3 Commonwealth L Bull 417 and OP Motiwal, "The Principles of Legislative Drafting" (1974) 16:1 J Indian L Inst 11 at 25. For a critical discussion on the plain language movement, see Mark Adler, "The Plain Language Movement" in The Oxford Handbook of Language and Law, supra note 1 at 67.

19. See "Vision, Mission and Objectives", supra note 10 , where the terms 'clarity' and 'precision' are used synonymously. See also Guide to Making Federal Acts and Regulations, supra note 9 at 116, where the terms 'ambiguity' and 'vagueness' are incorrectly used as synonyms here.

20. Fuller, supra note 7. 
the concept of clarity and the concept of precision in this text-one which will inform the analysis made in the latter portions of this paper.

The purpose of law is to "subject human conduct to the governance of rules", writes Fuller. ${ }^{21} \mathrm{~A}$ lawmaker seeks to govern human conduct by enacting rules. In describing the existence conditions for a legal system, Fuller states that wherever law exists lawmakers must have complied with the formal constraints on lawmaking, to a certain extent. He proceeds to outline what these formal constraints are and arrives at eight desiderata which are often referred to as the "principles of legality'.

Fuller arrives at the principles of legality through a parable about an imaginary ruler, Rex. ${ }^{22}$ Rex tries to enact rules that effectively guide human behaviour. Rex fails to do so on eight counts. Discussing each of Rex's failures, Fuller outlines eight principles of legality. These are as follows: (i) laws must consist of general rules; (ii) laws must be publicised; (iii) retroactive legislation must be used within adequate bounds; (iv) laws must be as clear as possible; (v) laws must be noncontradictory (it must not be the case that one law can only be obeyed by violating another); (vi) laws must not demand the fulfilment of impossible actions by the subjects; (vii) laws must possess sufficient stability over time; and (viii) laws must be congruent- "officials must act and decide on the basis of and in accordance with the law". ${ }^{23} \mathrm{~A}$ total failure to comply with any one of these formal principles, results in something that cannot be properly called a system of law. ${ }^{24}$ Therefore, there is a necessary connection between a certain degree of compliance with the principles of legality and the existence of law.

Fuller's list of eight desiderata is a surprisingly comprehensive set of existence conditions for a legal system. Even Fuller's theoretical rivals, the legal positivists, endorse Fuller's list. What legal positivists take issue with is Fuller's claim that these formal principles amount to an internal morality of law. ${ }^{25}$ This contentious claim will not be discussed in this paper. Instead, I focus on desideratum (iv) in Fuller's list - the desideratum of clarity. What does Fuller mean when he says that laws must be as clear as possible?

Fuller notes that the desideratum of clarity has been only marginally discussed in jurisprudence. He attributes this failure to the positivists who, owing to their reluctance to admit that an unclear law is less a law than a clear one, have only very briefly addressed the concept of clarity. ${ }^{26}$ Whether or not Fuller is correct in attributing this failure to the positivists, he correctly points at the lack of literature

21. Ibid at 74 .

22. Ibid at 33 .

23. Ibid at 39.

24. Ibid at 39-40.

25. Matthew Kramer argues that Fuller admirably describes the rule of law through the eight desiderata, but fails to show that these principles hold moral value. See Matthew H Kramer, "On the Moral Status of the Rule of Law" (2004) 63:1 Cambridge LJ 65.

26. Fuller, supra note 7 at 63 . See also Fuller, supra note 7 at 74 , for Fuller's discussion on how and why the positivists overlooked the desideratum of clarity. 
on clarity-highlighting the scarce treatment given to the topic in the works of the likes of Bentham and Austin. ${ }^{27}$

It is in this contextual backdrop that Fuller's discussion of clarity is important. Fuller criticises "obscure and incoherent" legislations, arguing that it is the legislature's responsibility to ensure that such laws are not drafted. ${ }^{28}$ However, in an often overlooked paragraph in his book, Fuller takes issue with what he calls "specious clarity". ${ }^{29}$ Drawing from Aristotle, he agrees that we cannot be more exact than the nature of the subject matter we are dealing with. ${ }^{30}$ Through this statement, he concedes that there are cases in which we cannot be exact or precise in drafting laws. So, in these cases where exactness is not possible, a "specious clarity" is much more damaging than an "honest open-ended vagueness". 31

Fuller is thus distinguishing between two concepts: clarity and exactness or precision. While aspiring for the former prevents obscure and incoherent legislation, the latter is neither achievable nor desirable in certain cases. In cases where precision is impossible, Fuller admits that an "honest open-ended" vagueness can be of value. Contrary to what Fuller intended, our understandings of the rule of law often have very little room for this open-minded vagueness.

\section{Clarity, Precision and Vagueness}

A close reading of Fuller necessitates properly distinguishing between the concepts of clarity and precision. Fuller tells us that clarity is important to strive for. I agree. I will establish that clarity is correctly contrasted with ambiguity and precision is correctly contrasted with vagueness. It is important to distinguish between these concepts to understand what our goal is. If we must strive for clarity, our goal is to eliminate ambiguity. It is not to eliminate vagueness.

Ambiguity is different from vagueness. An ambiguous word has more than one meaning and creates confusion about which meaning is in use. ${ }^{32}$ Philosophers of language uphold this definition of ambiguity and tell us that ambiguity can be of many types. ${ }^{33}$ The simplest case, similar to what has just been discussed, is a case of lexical ambiguity - wherein a single term has two or more meanings. ${ }^{34}$ Consider the word pupil. In one sense, the word pupil refers

27. Ibid at 63 .

28. Ibid at 64 .

29. Ibid.

30. Ibid.

31. Ibid. Fuller refers to standards (as distinguished from rules) like "good faith" and "due care".

32. Lawrence M Solan, "Vagueness and Ambiguity in Legal Interpretation" in Vagueness in Normative Texts, supra note 4 at 73 and Jeremy Waldron, "Vagueness in Law and Language: Some Philosophical Issues" (1994) 82:3 Cal L Rev 509 at 512. Waldron states that "an expression $\mathrm{X}$ is ambiguous if there are two predicates $\mathrm{P}$ and $\mathrm{Q}$ which look exactly like $\mathrm{X}$, but which apply to different, though possibly overlapping, sets of objects, with the meaning of each predicate amounting to a different way of identifying objects as within or outside its extension."

33. Simon Blackburn, The Oxford Dictionary of Philosophy, 2d ed (Oxford University Press, $2005)$ at 12 .

34. Ibid. 
to a black hole located in the center of the iris of a human eye. In another sense, the word pupil refers to a student in an educational institution. If the word pupil is used without clarification and context, lexical ambiguity may arise regarding the use of the word.

There are several other types of ambiguity as well such as structural ambiguity, systematic ambiguity, type-token ambiguity and object-act ambiguity. ${ }^{35}$ While a detailed discussion on ambiguity falls outside the scope of this paper, it is important to note that ambiguity leads to obscurity and a lack of clarity in a general sense. The receiver, listener or reader is unsure which meaning of the word is being used.

This ambiguity leads to a lack of clarity in the Fullerian sense - an obscurity through which the reader of a law does not know to what the law refers. What do the words in a statute mean, considering there are at least two meanings? Such ambiguity is to be avoided, Fuller tells us, to ensure that the goal of legislative clarity is achieved.

This is largely indisputable. We must know which meaning of a word is being referred to in a law to be able to follow it. And so, if we accept that we need to strive for clarity, we must seek to eliminate ambiguity.

While clarity should be aspired for and ambiguity should certainly be reduced, the same cannot be said for the precision-vagueness binary. Vagueness is different from ambiguity. ${ }^{36} \mathrm{~A}$ vague word, unlike an ambiguous one, has only one meaning but its application is unclear. An expression is vague if there are borderline cases for its application. ${ }^{37}$ When there are no borderline cases for the application of an expression, it is a precise expression. ${ }^{38}$

I will discuss the concept of borderline cases in the next part of this section. For now, I want to call attention to the differences between clarity and precision, and the distinction between ambiguity and vagueness. I agree with Fuller (as I suspect most legal theorists do): we must reduce ambiguity, as we have to strive for clarity. The same cannot be said for vagueness. I will argue that vagueness is both inevitable and sometimes desirable over precision in legal language. And so, vague words do not necessarily make for bad laws.

\section{The Inevitability and Limited Desirability of Vagueness}

In this section, I will draw from central debates in jurisprudence on the nature of language and its role in legal processes to argue that the desire for precision and the need to over-define legal terms is flawed. To do so, it is crucial to first frame the argument made by those in favour of eliminating vagueness. The argument against vagueness can be summarised using the three premises and the conclusion that follows:

35. Ibid.

36. Solan, supra note 32 at 73 .

37. Endicott, supra note 2 at 31.

38. Ibid. 
P1: Vagueness is the opposite of precision

P2: Precision is always achievable

P3: Precision is always desirable

$\mathrm{C}$ : Therefore, precision must be strived for over vagueness.

While I agree with P1 (as I have shown vagueness is correctly understood as the opposite of precision), I take issue with $\mathrm{P} 2$ and $\mathrm{P} 3$ in this paper. If $\mathrm{P} 2$ and $\mathrm{P} 3$ are false, conclusion $\mathrm{C}$ does not follow. I hope that this analysis can conclusively demonstrate the flaws in the above-mentioned argument and caution against its use in policy, academia and the practice of legal drafting.

\section{A. Inevitability}

Legal philosophers are interested in studying the concept of law. Central to legal philosophy are questions on the relationship between law and language. I will briefly enter the jurisprudential debate on legal interpretation and language to demonstrate that a study of the philosophy of language leads us to the conclusion that vagueness is inevitable. Efforts to eliminate vagueness are redundant.

H.L.A. Hart's classic jurisprudential text, 'The Concept of Law', is an effective entry point into the law-language discussion in the context of judicial interpretation. In Chapter 7, Hart discusses a middle-ground theory between the two prevalent approaches that he refers to as "formalism" and "rule-skepticism". 39 Formalism can take two forms. In its descriptive form, formalism is the claim that all judicial decisions are clearly determined by pre-existing legal rules. ${ }^{40}$ In its prescriptive form, formalism is the claim that all judicial decisions should be clearly determined by pre-existing legal rules. ${ }^{41}$ On the other hand, rule sceptics argue that pre-existing legal rules almost never guide judicial making. ${ }^{42}$

Hart argues that while the formalists or textualists fail to account for the "open texture of language", the rule sceptics exaggerate the reach of this very open texture. ${ }^{43}$ Hart tries to forge a middle ground between these two theoretical positions, which he constructs as opposing extremes on a theoretical continuum.

For Hart, all words and general legal concepts have a core of settled meaning or certainty and a "penumbra" of uncertain application or doubt. ${ }^{44}$ Judges must check if the case is a core case. This classification is not a purely logical deductive process. While it is obvious that some instances fall within the "core" of settled meaning, in other cases, the classification is uncertain. ${ }^{45}$ In these penumbral

39. HLA Hart, The Concept of Law, $2 \mathrm{~d}$ ed, Penelope A Bulloch \& Joseph Raz, eds (Oxford University Press, 1994) at 124.

40. Ibid at 124-36.

41. Ibid.

42. Ibid.

43. Ibid at 138. For the rule sceptics, "there is nothing to circumscribe the area of open texture" according to Hart.

44. Ibid at 123 .

45. Ibid. 
cases, pre-existing rules cannot guide judicial decision-making. ${ }^{46}$ Hart's middle ground suggests that pre-existing legal rules clearly regulate judicial decisions, but only in core cases and not in penumbral or borderline cases. Judges must check if the case is a core case. If it is, they must apply the pre-existing legal rule. If not, the case falls outside the scope of the law. They must then apply their own discretion to decide the case at hand. Their decisions are no longer within the ambit of the pre-existing rule or the law.

Hart's middle ground manages to capture a certain intuitive idea of judicial decision-making. Rules seem to clearly guide judicial verdicts, unless the words in themselves are vague. This construction of adjudication lends itself to the instructions given to legal drafters to eliminate vague words and reduce the possibility of borderline or penumbral cases..$^{47}$ The problem, however, is that while the jurisprudential conversation on this topic has advanced greatly from where Hart left us, the real-world approaches to policy and drafting seem to be still greatly informed by a Hartian understanding of the core and the penumbra. If understood through the Hartian core-penumbra frame, drafters seek to clearly outline the core and distinguish it from the penumbra, whilst simultaneously trying to eliminate or reduce the possibility of penumbral cases.

This approach to drafting statutes fails. Hart's middle ground theory has come under attack, particularly for its failure to understand vagueness and the inevitable structural complexities of human language. Though Hart does briefly acknowledge that open-ended standards are sometimes effective, his theory is based on a construction of rules as precise maxims by which people can regulate their behaviour (even though in some exceptional cases vague standards may be adopted). ${ }^{48}$ Hart's theory is thus incomplete because he fails to account for the extent and prevalence of vagueness in legal rules. When we understand vagueness, we see that words often lack a clear core of settled meaning - and thus, Hart's distinction of core and penumbral cases does not capture the complexities of vagueness.

Let us then briefly survey the recent jurisprudential conversation on vagueness. Philosophers of language have extensively discussed 'vagueness' or vague predicates. A vague predicate is defined by a lack of a sharp linguistic boundary ${ }^{49} \mathrm{~A}$ predicate $\mathrm{A}$ is vague if there are instances in which it is not

46. Ibid.

47. This is because an instruction to reduce vagueness is an instruction to reduce the possibility of borderline cases. However, it is important to note that since Hart has not discussed linguistic vagueness at great length, there is nothing to say that Hart is necessarily committed to the position that there is a clear demarcating line between the core and penumbra which eliminates vagueness. More recent work on vagueness, thus, is not necessarily incompatible with the Hartian position and can sometimes be constructed as an extension of Hart's work.

48. Hart, supra note 39 at 131-32. Hart writes that, "In fact all systems, in different ways, compromise between two social needs: the need for certain rules which can, over great areas of conduct, safely be applied by private individuals to themselves without fresh official guidance or weighing up of social issues, and the need to leave open, for later settlement by an informed, official choice, issues which can only be properly appreciated and settled when they arise in a concrete case". However, Hart cannot reconcile these comments with his broader core-penumbra conception that he presents as his theory of adjudication.

49. Fred Ablondi, "Overview: Vagueness" (1999) 25 Philosophy Now 20. 
determinate whether some object ' $\mathrm{x}$ ' is A or not. ${ }^{50}$ At what point of hair loss is a person deemed to be bald? We cannot clearly say. This is the philosophical problem of 'vagueness'.

Consider $n$ is the amount of hair on a person's head. For any $n$, if $x(n)$ is bald, then $x(n+1)$ is bald. This would mean that if $x(n+1)$ is bald, then $x(n+2)$ is bald and so on. If we apply this reasoning, we are led to the (clearly absurd) conclusion that even a person with a full head of hair is bald. ${ }^{51}$ This seems false, but we seem to have reached this conclusion by a sound chain of reasoning. Can the answer lie between $n+1$ and a man with a full hair of head? Timothy Endicott says that legal cultures adopt the belief that the addition or subtraction of one strand of hair will not affect the application of the word 'bald', though a sufficient change in the number of hairs will do so. ${ }^{52}$ Endicott calls this the 'tolerance principle'. ${ }^{53}$ Where on this continuum does the answer lie, though? At what point of hair growth will a person lose their baldness?

Indeed, Hart's failure can be most accurately understood by reference to the Sorites Paradox. ${ }^{54}$ The paradox involves a heap of sand, from which grains are individually removed. Suppose we remove a single grain at a time, at what point does the heap change from a heap to a non-heap? There is no clear point we can outline. There is no determinable boundary between the core and the penumbra.

These issues capture the problem with Hart's account. At what point does the core give way to the penumbra? We do not know. When we try to determine a clear boundary line for where the core ends and where the penumbra begins, we are engaged in an exercise that is both impossible and futile. The inevitability of vagueness in human language, no matter how well or precisely words are defined, is not something that drafters can escape.

Therefore, vagueness is inevitable in the structures of human language. Legal theorists have debated the extent of this vagueness - arguing about whether we can never know what particular instances a general word applies to (the 'radical indeterminacy thesis') or whether we often do not know this (the moderate thesis). ${ }^{55}$ Whichever of these approaches we take, we must accept the fact that more often than not, vagueness is inevitable in the process of drafting legal rules. If we accept the inevitability of vagueness in the process of legal rulemaking, we can better deal with the challenges it poses for legal systems.

Therefore, we often cannot achieve precision. Efforts to achieve precision i.e. to clearly outline the boundary line between the core and penumbra are thus

50. Ibid.

51. Endicott, supra note 2 at 34 .

52. For a discussion of this tolerance principle in an applied manner, see Gunnar Beck, The Legal Reasoning of the Court of Justice of the EU (Hart, 2013).

53. Endicott, supra note 2 at 34.

54. Ibid at 1 . For discussions on the Sorites Paradox, see generally Dominic Hyde, "The Sorites Paradox" in Giuseppina Ronzitti, ed, Vagueness: A Guide (Springer, 2011) and Timothy AO Endicott, "Vagueness and Legal Theory"(1997) 3:1 Leg Theory 37.

55. Endicott discusses the flaws of the radical indeterminacy thesis in Timothy AO Endicott, "Linguistic Indeterminacy" (1996) 16:4 Oxford J Leg Stud 667 at 670. 
ineffective. As vagueness is inevitable in the languages that human beings use (as compared to a perfectly scientific-logical language) ${ }^{56} \mathrm{P} 2$ is disproved.

Having shown that $\mathrm{P} 2$ is false, we have reason enough not to strive for precision. It makes hardly any sense to aim for precision if this is an impossibility. However, I will go a step further to prove that vagueness is not only inevitable, but also, desirable. Vagueness can have value.

\section{B. Desirability}

By arguing that vagueness is inevitable, I have made a descriptive claim. I will now proceed to make a second, normative claim about vagueness: vagueness can have value. If this is shown, P3 cannot stand. Precision is not always desirable if vagueness sometimes is.

Contrary to the prevalent conception of vagueness as a problem in legal language, some legal philosophers have made a case in favour of vagueness. While Jeremy Waldron claims that it furthers people's own ability for practical deliberation, Endicott argues that vagueness is a necessary route in certain legal spheres. ${ }^{57}$ Endicott points to what he calls the 'normative principle'-a norm must provide a reason for action, and a purpose. ${ }^{58} \mathrm{~A}$ norm that does not abide by this principle is arbitrary and lacks a reasoned justification. ${ }^{59}$ For any norm to be adopted, it must be arbitrary to the minimum and we must have good reasons for adopting it.

Using Endicott's 'normative principle', let us discuss P3. According to P3, precision is always desirable. Is this norm reasonable? Or does it also give way to arbitrariness? Endicott argues that the need for precision can lead to arbitrary consequences, just like vagueness can. ${ }^{60}$ Both precision and vagueness, thus, are arbitrary to different degrees in different contexts.

Consider the example of laws that provide a minimum age for alcohol consumption. In most jurisdictions, the law stipulates that a person must be above a certain age to be able to legally drink. This age is set at eighteen years of age in some jurisdictions, while others choose a lower or higher age limit. The reason behind age requirements for alcohol consumption is that due to alcohol's

56. Waldron supra note 32 at 522 notes that logicians have dreamt of an ideal scientific knowledge that would eliminate vagueness. See Gottlob Frege, "Grundgesetze der Arithmetik" in Peter Geach \& Max Black, eds, Translations from the Philosophical Writings of Gottlob Frege, 2d ed (Blackwell, 1960) at 159. Frege describes concepts of this perfect language saying: "A definition of a concept ([i.e.,] of a possible predicate) must be complete; it must unambiguously determine, as regards any object, whether or not it falls under the concept ([i.e.,] whether or not the predicate is truly assertible of it). Thus, there must not be any object as regards which the definition leaves in doubt whether it falls under the concept .... We may express this metaphorically as follows: the concept must have a sharp boundary."

57. Hrafn Asgeirsson, "On the Instrumental Value of Vagueness in the Law" (2015) 125:2 Ethics 425.

58. Timothy AO Endicott, "The Value of Vagueness" in Philosophical Foundations of Language in the Law, supra note 1 at 20.

59. Ibid.

60. Ibid. 
intoxicating effects, a person must have reached an adequate stage of maturity to be able to drink and take responsibility for their actions. In jurisdictions where eighteen years is set as the age, certainly not everyone above the age of eighteen years can be said to possess the required level of maturity and not everyone of below eighteen years of age can be said to be lacking in this maturity. The precise age limit is thus arbitrary.

However, in a case like this, vagueness would also lead to arbitrariness. If there were a legal standard that permitted those 'mature enough to handle alcohol' to consume alcohol, the case-by-case determination of whether people had this maturity to drink or not would be left to those selling alcohol. This power could easily be abused. As Endicott notes, in cases like this, perhaps the "arbitrariness of the precise standard may itself have an important expressive function, signifying the community's refusal to draw invidious distinctions among persons". ${ }^{61}$ In cases like this, both precision and vagueness are arbitrary-but the arbitrariness of the former is preferred because of the area of law and the context in which regulation occurs. Therefore, when regulating different forms of conduct, we must ask whether vagueness or precision are less arbitrary and regulate conduct accordingly.

As critics of vagueness argue, the arbitrariness of vagueness lies in the fact that it vests judges with what some regard as excessive judicial discretion. Their main problem is that the use of vague language allows for unguided judicial discretion. Endicott suggests using the 'Similarity Model' to tackle this issue. ${ }^{62}$ According to this model, a term will apply to an object if the object resembles the paradigm sufficiently in relevant respects. ${ }^{63}$ To obtain more clarity on how judges can apply the model, I suggest turning briefly to Ludwig Wittgenstein. ${ }^{64}$ Wittgenstein's theory of 'family resemblances' can explain vagueness in the following manner:

Sometimes a word is vague not because there is a single cut-off point, but because there are multiple criteria for its application. A term may be associated with characteristics A, B, C, D and E. But if a thing has A, B and C, the term may apply without D or E. Or it can have B, C, D and A and still apply. ${ }^{65}$

This account clearly captures the complex, contextual relationship that words share with meaning. The meaning of words is not settled in isolation of context, and is not a determinable core, as Hart suggests. In this scenario, then, determining whether or not a thing can be classified under a term requires a judge to interpret whether the word fits within a larger interpretative family or not. The question of whether a thing resembles a term in the relevant ways involves a

61. Ibid at 22 .

62. Endicott, supra note 2 at 31 .

63. Ibid.

64. For a discussion on Wittgenstein's theory of family resemblances and its repercussions for vagueness, see Endicott, supra note 2 at 47-8.

65. For an introductory analysis to Wittgenstein's theory, see generally John Hospers, $A n$ Introduction to Philosophical Analysis, 4th ed (Routledge, 2013) at 22 and Leon Pompa, "Family Resemblance" (1967) 17:66 The Philosophical Quarterly 63. 
complex adjudicatory deliberation. The arbitrariness of vagueness thus can be dealt with by developing techniques that judges can follow to adjudicate cases meaningfully and tackle the problem of vagueness. ${ }^{66}$

In conclusion, both precision and vagueness can be arbitrary. We need to weigh which form of arbitrariness is worse, and in what legal context. While precision is sometimes desirable, so is vagueness. Thus, as a norm, vagueness possesses 'limited desirability'-it is desirable in some cases over precision, but not in others.

P3 states that precision is always desirable-a premise that, thus, collapses. While precision may sometimes be more desirable than vagueness, presenting precision as the default option and the aspirational goal for legal drafters is based on flawed theoretical assertions such as P3.

In the next two sections of this paper, I will examine this jurisprudential insight on vagueness through the lens of feminist theory. I hope that these reflections can centralise feminist theory in the current jurisprudential debates on law and language.

\section{Vagueness as a Feminist Value}

Having shown that the argument against vagueness is unsuccessful, I will proceed to make a case in favour of vagueness. Reflections in feminist theory can reveal the value-both intrinsic and instrumental-that vagueness possesses. ${ }^{67} \mathrm{I}$ will discuss the potential intrinsic value of vagueness in this section of the paper and in the next section, I will discuss the instrumental value of vagueness for certain areas of law.

I locate my preliminary analysis on intrinsic value within feminist philosophy by engaging with feminist perspectives to central epistemological questions. While feminist philosophies diverge significantly in their methods and conclusions, ${ }^{68}$ they share (some form of) the following core ideas. First, feminist philosophies are all in some sense "engaged" with the project of destabilizing status quo as established by traditional non-feminist philosophical schools. Second, feminist philosophies, irrespective of their divergences, agree that gender matters for philosophy in some way or another. ${ }^{69}$ They see the alleged neutrality of the canonical traditions as being a problematic political stance that in fact normalizes gendered power relations.

66. Ronald Dworkin's theory of interpretivism could be useful as a guidance tool for judges in an interpretative exercise. See Ronald Dworkin, Law's Empire (Harvard University Press, 1986). Asgeirsson also lays down suggestions for judges on how to approach vagueness in words through his theory of adjudication in Asgeirsson, supra note 2.

67. Vagueness can be valuable as an end in itself or as a means towards other valuable ends. In Asgeirsson, supra note 57, Asgeirsson argues that Endicott and Waldron wrongly associate vagueness with instrumental roles that are really played by incommensurate multidimensionality, a phenomenon different from but closely related to vagueness.

68. See McAfee, supra note 6 and Ann Garry, Serene J Khader \& Alison Stone, eds, The Routledge Companion to Feminist Philosophy (Routledge, 2017). They discuss the divergences amongst feminist philosophers of different orientations.

69. McAfee, supra note 6. 
Feminist philosophies across orientations are thus likely to be more "perspectival, historical, contextual, and focused on lived experience than their non-feminist counterparts." $" 70$

In light of these core commitments, feminist philosophers challenge certain epistemological constructs that mainstream philosophers take for granted. I focus on the feminist critique of one such construct: the Cartesian dualism. The Cartesian dualism continues to be the subject of contemporary feminist critique. ${ }^{71}$ An understanding of the dualism helps set the stage for our discussion on vagueness and its value as constructed from a feminist perspective.

The Cartesian dualism is located in the context of a larger epistemological debate between the rationalists and the empiricists on our sources of knowledge and truth. ${ }^{72}$ While rationalists argue that we can gain knowledge independently of sense experience, empiricists claim that sense experience is the fundamental source of knowledge. ${ }^{73}$ Empiricists like Aristotle, Hobbes and Hume establish (in different ways) that experience is the primary source of knowledge and the only way we understand concepts around us. This view finds contestation in the rationalist philosophies of Plato and then, René Descartes'. Descartes' body of work-Cartesianism-forms the backdrop for the dualism.

Descartes' rationalist position was premised on the notion that our senses are unreliable and thus cognition or reason is the only route to arriving at true knowledge about existing phenomena. ${ }^{74}$ While we can doubt everything our senses tell us, reason and our capacity for cognition are beyond doubt-as they are that which doubts. ${ }^{75}$ By constructing the mind as separate from the realm of sensory experience, Descartes furthered the notion of the disembodied self. The essential self was to be distinguished from the physical body, and as a result the mind's capacity for reason and cognition was distinguished from the body's capacity for sensory experience and emotion. ${ }^{76}$ This distinction came to be known as the Cartesian mind/body dualism.

The Cartesian dualism set the stage for the view that the mind is an incorporeal entity and is separate from the physical body. The implications of this were that a host of other values were constructed in the frame of a dualism: reason/emotion,

70. Ibid.

71. See the discussions on the dualism in Steven Nadler, Tad M Schmaltz \& Delphine AntoineMahut, eds, The Oxford Handbook of Descartes and Cartesianism (Oxford University Press, 2019). Marie-Fréderique Pellegrin also discusses the larger interplay between Cartesianism and feminism in this book, ibid at 565-582.

72. Marleen Rozemond, Descartes's Dualism (Harvard University Press, 1998).

73. Peter Markie, "Rationalism vs. Empiricism" in Edward N Zalta, ed, The Stanford Encyclopedia of Philosophy (2004) (Fall 2017 Edition), online at https://plato.stanford.edu/archives/ fall2017/entries/rationalism-empiricism.

74. See Rene Descartes, Discourse on Method and Meditations on First Philosophy, translated by Donald Cress (Hackett, 1980).

75. Ibid at 63. Descartes asks, "But what then am I? A thing that thinks. What is that? A thing that doubts, understands, affirms, denies, wills, refuses, and which also imagines and senses."

76. Ibid at 93 . While the mind is a thing that thinks for Descartes, the body is an extended thing and not a thing that thinks. 
culture/nature, rationality/irrationality. ${ }^{77}$ The first term in these dualisms is associated with the mind and the realm of cognition, while the second is associated with the physical body and the zone of sense experience in the Cartesian frame. Importantly, the first term of these dualisms was also given priority over the second. This follows from Descartes' prioritisation of the mind over the body.

Empiricist critics of the Cartesian dualism like Hobbes, Spinoza and Hume, along with pragmatists like John Dewey challenged the structure of oppositional binaries embedded within the Cartesian frame-reason/emotion, thought/practice and the universal/particular. ${ }^{78}$ While these challenges either critique Descartes' rationalism or show the dualism is incorrect as it falsely bifurcates the mind from the body, ${ }^{79}$ the feminist contribution to the critique of the Cartesian dualism is unique. Feminist philosophers called into question the gendered nature of the Cartesian dualism.

For feminist philosophers, the Cartesian dualism and the other dualisms that followed are not only false as they value one attribute at the expense of the other, but are also deeply gendered. ${ }^{80}$ The first term in each of these dualisms is a value of the public sphere-associated, materially and symbolically, with men. ${ }^{81}$ The second term is a value relegated to the private sphere and associated culturally with women. ${ }^{82}$ The reason/emotion dualism, for instance, fits neatly into this frame as while reason has been constructed as a value of the public sphere that men are associated with, women have been problematically constructed as being emotional and belonging to the private sphere. This gendering is of crucial importance, particularly because of the hierarchy that is implicit in the gendering of these dualisms. ${ }^{83}$

Apart from disputing the gendered nature of the dualisms, feminist philosophers argue that the association of values with gender roles is culturally (though definitely not biologically) produced. ${ }^{84}$ They dispute the claim of hierarchy, or the idea that the values and practices associated with the public sphere are necessarily better than those associated with the private. For instance, while reason is

77. For a discussion of some of the dualisms that follow from the mind/body dualism, see Antonio R Damasio, Descartes' Error: Emotion, Reason and The Human Brain (Penguin Random House, 2005); Edward Craig, ed, Routledge Encyclopedia of Philosophy: Descartes to Gender and Science (Routledge, 1998) vol 3 at 200; Douglas A Vakoch \& Sam Mickey, eds, Women and Nature?: Beyond Dualism in Gender, Body, and Environment (Routledge, 2017).

78. Markie, supra note 73.

79. Vakoch \& Mickey, supra note 77.

80. Ibid. See also David Knights \& Deborah Kerfoot, "Between Representations and Subjectivity: Gender Binaries and the Politics of Organizational Transformation" (2004) 11:4 Gender, Work and Organization 430; Jane Duran, "The Intersection of Pragmatism and Feminism" (1993) 8:2 Hypatia 159; Genevieve Lloyd, The Man of Reason: 'Male' \& 'Female' in Western Philosophy, 2d ed (Routledge, 2002).

81. Nick Butler \& Stephen Dunne, "Duelling with dualisms: Descartes, Foucault and the history of organizational limits" (2012) 7:1 Management \& Organizational History 31 at 34.

82. Ibid.

83. Knights \& Kerfoot, supra note 80 at 431.

84. Susan Bordo, "The Cartesian Masculinization of Thought" (1986) 11:3 Signs: Journal of Women in Culture and Society 439 at 455. 
an important source of knowledge for human beings, our emotions, and our capacity to care for one another, can also be important sources with which we can understand the world. Therefore, feminist philosophies urge us to contest, rather than further, both the binary and the entrenched hierarchy embedded with the dualism. We must ask, then, whether the second term in the dualisms is of value. If the term is of value in its own right, it must be reclaimed. This reclamation contests the hierarchical ordering of the Cartesian dualism.

Let us now turn to our discussion on vagueness. As established in Section 1 and 2 of this paper, precision and vagueness are opposites of one another. While precise words are those words that have significantly eliminated penumbral or borderline cases, vague words are characterised by these penumbral cases. The vagueness-precision oppositional serves as an interesting point of analysis.

If we look closely at the vagueness-precision binary, we recognise that vagueness and precision can also be classified within the frame of the Cartesian mind/ body dualism. While precision is associated with the site of the mind and the need for a scientific exactness, vagueness leaves space for the subjectivities associated with sensory experience.

Let us first consider precision and its association with the realm of the mind and cognition in the Cartesian frame. In legal cultures, the attempt at precision requires that words be technically accurate, and definitions be crafted with scientific and logical dexterity. This is the only way penumbral cases can be eliminated. Further, the emphasis on precision in law also assumes that rules can be drafted to accommodate for all future possibilities at the stage of drafting laws. At the stage of drafting a law, drafters are not aware of the unique set of cases and circumstances to which a rule will be subject. If the rule is to be defined as precisely as possible, the assumption is that the rule can be defined best at the stage of abstraction rather than at the adjudicatory stage. This reliance on objectivity, scientific reason and abstraction makes precision much like the first terms in the dualisms we have discussed.

Having discussed precision, we can now turn to discussing vagueness within this vagueness-precision binary. What does vagueness do that precision does not? Unlike the goal of precision, vagueness leaves open space for particularity, context, and subjectivity. How? First, when words are left vague at the stage of drafting legal rules, discretion is given to judges at the stage of adjudication. The subjective realities of each litigants' experience can thus be accommodated for at the stage of adjudication by embracing vagueness. Second, vagueness leaves room for context. It centralises lived experiences of people. When legal rules can be interpreted to accommodate for the unique experiences of parties, the particular facts at hand can be better regulated. Therefore, vagueness leaves room for particularity, context, and subjectivity—and for doubt. ${ }^{85}$

85. The penumbra is the realm of doubt for Hart. See Hart supra note 39 at 123. 
Vagueness thus is valuable. The project of ensuring justice through a system of legal rules requires that the rules have the ability to take into account the complexities of each particular case. Precision and its insistence on abstraction reduces the scope for complexity and undermines context. Vagueness's value is rooted in its understanding of this context and its sensitivity to the lived experience of people who are governed by rules. While precision serves the higher-order good of ensuring predictability, ${ }^{86}$ vagueness serves the higher-order good then of flexibility and context-sensitivity. It accounts for the multitude of things that cannot be known at the stage of abstraction — or at the drafting stage - and thus, contributes through this context-sensitivity to the larger project of ensuring justice.

This value of vagueness is in line with the project of feminist philosophy. Feminist philosophers argue that philosophical thought often highlights the universal over the particular, by emphasising abstraction over context. ${ }^{87}$ Universal, abstract knowledge that can be arrived through pure "cognition" is contrasted with particular, context-specific knowledge that varies based on sensory experiences. This hierarchisation is deeply gendered. If women, trans or gender non-confirming people's experiences, across social locations, have to be accommodated in the process of doing philosophy, ${ }^{88}$ there must be an emphasis on particularity, fluidity and context—which universalised, abstract knowledge-creation suppresses.

Legal cultures seek to curb subjectivity and neutralise context by reducing vagueness and strive to make legal language as precise as possible. This hierarchisation of precision over vagueness in legal cultures takes the same form as the dualisms we have discussed: it prioritises the first term in the dualism over the second.

However, vagueness (the second term in the binary) uniquely allows for context-sensitive legal cultures that manage to centralise lived experiences of people. The second term in the binary is thus also of value. Vagueness makes room for context-sensitivity and the particularities of lived experience; it can be seen as a value from the lens of feminist philosophy. For these reasons, it becomes important to reclaim vagueness and recognise its value.

\section{Vagueness and Feminist Work in Law: Of All the Things We Cannot Know in Advance}

Drawing from these philosophical insights, I will now outline certain areas of law in which vagueness is valuable. While it is not my intention to provide an exhaustive list of such areas, I identify two realms — each, both theoretical and doctrinal-where

86. As Fuller notes in his discussion on clarity and in the function of law which is to subject human conduct to the governance of rules. See Fuller, supra note 7 at 74 .

87. There is a rich tradition in philosophy which emphasizes the subjective over the objective. Hume is a great example. See Gilles Deleuze, Empiricism and Subjectivity: An Essay on Hume's Theory of Human Nature, translated by Constantin V Boundas (Columbia University Press, 2001) and Rosalyn Diprose, "What is (Feminist) Philosophy?" (2000) 15:2 Hypatia 115.

88. To accommodate these experiences, there must be a rejection of the precise boundaries (and binaries) that mainstream legal cultures endorse. Vagueness acts as a linguistic tool towards this end. 
vagueness is certainly of value. These realms are identified by drawing from two areas of feminist theory - the ethics of care and the conception of intersectionality. I use the former to discuss issues posed by family law and the latter to evaluate the challenges posed by discrimination law. ${ }^{89}$ Framing these theoretical-doctrinal realms helps identify both, the complexities of the social phenomena and the legal issues at stake, which are best regulated through the use of vague language.

While the ethics of care and intersectionality are distinct (and arguably conflicting) theoretical endeavours, ${ }^{90} \mathrm{I}$ bring them together in this section primarily for two reasons. First, as I will demonstrate, the complex social phenomena at play that are addressed by both theories cannot effectively be addressed through the use of precise legal language. Both schools require us to accept the various things that we cannot know in advance at the temporal stage of drafting laws. Second, and following from this idea, both theoretical schools directly influence doctrinal areas of law wherein objective, precise words are often seen to fall short. These areas of law are perhaps best governed through subjective, contextual judgement at the adjudicatory stage. Therefore, while care ethics and intersectionality are indeed distinct endeavours within feminist theory, they are united in their rejection of the blanket hierarchisation of objective, abstract knowledge over subjective, contextual judgement. These crucial similarities make them amenable to being analysed in our discussion on vagueness.

\section{A. Relationality and Care}

There are some areas of law where vagueness is more valuable than precision. In this paper, I suggest that vagueness is more valuable than precision in areas of law that regulate personal relationships or relationships of care. To do so, I draw from the feminist ethics of care- - a frame, that though highly contested, remains one of the most influential ways of understanding relationships of care.

Care ethicists primarily derive their work from Carol Gilligan's landmark book, 'In a Different Voice' which has had a profound impact on feminist theory across disciplines. ${ }^{91}$ In her challenge to psychologist Lawrence Kohlberg's theory, which glorified the rational, autonomous reasoner as the epitome of moral

89. There has been significant work on these theoretical-doctrinal areas. For discussions on family law and the ethics of care, see Jonathan Herring, Caring and the Law (Hart, 2013). The discrimination law and intersectionality overlap can be seen in Shreya Atrey, Realising Intersectionality in Discrimination Law (Dissertation, DPhil, University of Oxford, 2015).

90. They could be constructed as contradicting theoretical claims if intersectionality is seen as problematising the homogenous idea of womanhood and care ethics is seen as endorsing this very idea. However, care ethicists have resisted essentialist and homogenising approaches to the notion of womanhood. See Chris J Cuomo, Feminism and ecological communities: an ethic of flourishing (Routledge, 1998). Cuomo argues that the logic that woman=feminine, feminine $=$ caring in a biologically essentialist manner is not a true representation of the care ethics position.

91. See Carol Gilligan, In A Different Voice: Psychological Theory and Women's Development (Harvard University Press, 1993). 
reasoning, Gilligan suggested that women grow to see individuals as shaped through connectedness, often linked through emotion and interdependent through care. ${ }^{92}$ This relational approach to ethics is a structurally "different voice" from the individualistic approaches in canonical moral philosophy which construct individuals as detached and disembodied. ${ }^{93}$ For care ethicists, this emphasis on relationality and subjectivity is an equally valid moral voice as compared to canonical moral theories that emphasise individualism and objectivity.

Care ethicists thus centralise particularity and context as important values within decision-making. They insist that crucial features of human life cannot, and should not, be judged without reference to context. Virginia Held describes care ethics as rooted within lived experiences, with an emphasis on embodiment and particularity. ${ }^{94}$ For Held, we can only understand relationality, particularly intimate relationships in structures such as families, if we pay attention to the context of each relationship and the lived experience of the relational actors. Stated simply, each relationship is different. Care is complex and subjective. We cannot judge the nature and the quality of relationships through tools of abstraction.

This paradigm shift from the detached positivist approaches in legal philosophy is crucial for our discussion on vagueness. When legal drafters are told to be precise, they attempt to use words in a manner that pre-existing legal rules can completely determine judicial decisions. ${ }^{95}$ But is this possible in areas of law that deal with intimate human relationships?

Consider the domain of family law. While we can share intimate relationships with persons outside heteronormative, patriarchal structures of families, family law continues to legally regulate a large part of intimate human relationships - or what are relationships of care. One of the most complex issues in family law are laws relating to child custody. Which parent should get custody of the child? Which parent is a "better" parent? Where will the child be given better and more care? A brief examination of these issues on custody reveals the complexity that care ethicists highlight.

The 'best interest of the child' threshold has been used almost universally to decide child custody disputes. Under the United Nations Convention on the Rights of the Child, "in all actions concerning children, whether undertaken by public or private social welfare institutions, courts of law, administrative authorities or legislative bodies, the best interests of the child shall be a primary consideration." 96

92. Ibid.

93. Ibid.

94. Virginia Held, The Ethics of Care: Personal, Political, and Global (Oxford University Press, 2006).

95. This is incompatible with the common law position on adjudication. For instance, see generally Shivprasad Swaminathan, "Mos Geometricus and the Common Law Mind: Interrogating Contract Theory" (2019) 82:1 Mod L Rev 46. However, even in common law systems, there is a preference for precision over vagueness at the stage of drafting statutes to reduce judicial discretion.

96. Convention on the Rights of the Child, UNGAOR, 20 November 1989, UN Doc 27531, art 3 (entered into force 2 September 1990). 
What is in the best interests of the child or what best furthers the child's welfare ${ }^{97}$ Time and again, there have been efforts in different parts of the world to make this threshold more precise. American legal scholar, Robert H. Mnookin, and others in the United States of America have insisted that the 'best interests' threshold should be replaced with a more objective rule, as it currently provides no direction to judges. ${ }^{98}$ In 2013, Carl Funderburk, a Special Judge in Oklahoma USA, wrote a controversial paper that argued that the best interest threshold should not be left vague especially in an area such as child custody. ${ }^{99}$ The best interests threshold has also been challenged in the American Supreme Court and the court has heard petitions to declare the threshold 'void for vagueness'. ${ }^{100}$ According to a brief submitted to the Supreme Court in Troxel v. Granville, "The best interests test has long been the subject of academic as well as judicial criticism for being indeterminate, providing little guidance on how to weigh the different needs of individual children, especially as they change over time. "'01

These calls to precisely define what lies in a child's best interests have been made in the United Kingdom ${ }^{102}$ and in several Nordic countries as well. ${ }^{103}$ Additionally, the Law Commission of India also suggested the need to discuss replacing the 'best interest threshold' with a more predictable rule-based law in its 257th Report. ${ }^{104}$ These developments, and perhaps several others across the world, are supported by academic texts that have suggested making the threshold more precise, as vagueness is fundamentally antithetical to the rule of law even in an area like child custody. ${ }^{105}$

This position on child custody laws is both flawed and dangerous. First, the need for precision in child custody laws is reflective of a larger legal culture that prioritises precision over vagueness at all costs. As I have discussed at length in

97. The best interest threshold is known to be "infamously vague". See Ram Rivlin, "Fairness in Allocations of Parental Responsibilities, and the Limits of Law" (2020) 33:2 Can JL \& Jur 397 at 418 .

98. Robert H Mnookin, "Child-Custody Adjudication: Judicial Functions in the Face of Indeterminacy" (1975) 39:3 Law \& Contemp Probs 226; Jon Elster, "Solomonic Judgments: Against the Best Interest of the Child" (1987) 54:1 U Chicago L Rev at 12-16; Martha L Fineman \& Anne Opie, "The Uses of Social Science Data in Legal Policymaking: Custody Determinations at Divorce" (1987) Wis L Rev 107.

99. Carl Funderburk, "Best Interest of the Child Should Not Be an Ambiguous Term" (2013) 33:2 Child Leg Rts J 229.

100. See also Hillary Rodham, "Children Under the Law" (1973) 43:4 Harvard Educational Review 487 at 513.

101. Troxel v Granville (2000), 530 US 57.

102. Rosalind English, "Analysis: Children's "best interests" and the problem of balance" (2 February 2011), online at UK Human Rights Blog https://ukhumanrightsblog.com/2011/02/ 02/analysis-childrens-best-interests-prevail-in-immigration-decisions [perma.cc/643Q-XS4H].

103. For a discussion on this, see Hannele Tolonen, Sanna Koulu, \& Suvianna Hakalehto, "Best Interests of the Child in Finnish Legislation and Doctrine: What Has Changed and What Remains the Same?" in Trude Haugli et al, eds, Children's Constitutional Rights in the Nordic Countries (Brill Nijhoff, 2019) 159.

104. Law Commission of India, Reforms in Guardianship and Custody Laws in India: Report No.257 (May 2015) [Report No.257], online at http://lawcommissionofindia.nic.in/reports/ Report\%20No.257\%20Custody\%20Laws.pdf [perma.cc/3B2B-JS2H].

105. Funderburk, supra note 99. See also Martin Guggenheim, What's Wrong with Children's Rights (Harvard University Press, 2009). 
this paper, precision is neither achievable nor is it universally desirable. We need to prioritise either precision over vagueness or vice versa depending on the area of law we are regulating.

Second, the area of child custody laws deals with a network of intimate relationships-parent and child, children with one another, parent and parent. The web of relationships involved here can only be appreciated on a case-to-case basis. An approach that seeks to define what constitutes better parenting at the stage of drafting a law misses the point about relationality.

As care ethicists note, the practice, labour and emotive value of care is complex and subjective. These aspects of care are hard to put a measure on through precise legal language. When pushed towards precision, drafters resort to drafting laws using objective metrics such as, which parent is better off financially, or which parent lives closer to the child's school, amongst other such factors. ${ }^{106}$

Such attempts at precision can create absurd judicial results. Often, the parent who qualifies for custody on an objective legal list, in fact, does not provide care — understood as labour and practice- towards their child. ${ }^{107}$ If we aim for precision over vagueness, judges must apply the law as it is and grant custody to the parent who is perhaps better off financially, but who certainly "cares less". This is the price we pay for precision. We make the wrong decisions, because we are so caught up in precisely defining rules through linguistic devices at the stage of drafting.

Drawing from the analysis in section 2, we know that no matter what we do, we cannot eliminate borderline cases or the possibility of vagueness in language. Instead, we must appreciate the role vagueness plays, as illustrated through our discussion of child custody laws. As care ethicists tell us, there is value in this subjectivity. For it is only through context and subjectivity that we understand relationships of care. The sooner we get comfortable with this subjectivity and vagueness, the better.

\section{B. Intersectionality and Discrimination}

Another area in which vagueness could be of more value than precision is discrimination law. The law on discrimination relates to incidents of unequal or unjust treatment based on a range of personal characteristics - a person's gender, caste, race, disability, national origin, religion, sexual orientation etc. These identities constitute different social locations, which often combine together to create discrimination of a compounded nature. Such discrimination can be addressed through the theoretical lens of intersectionality.

Intersectionality, within feminist theory, has gained currency as an important theoretical and political tool towards social justice and transformation. Traced

106. Indian courts have often resorted to using these factors when in search of an objective metric for determination of best interests. See also Report No.257, supra note 104.

107. Ibid. 
back to Kimberle Williams Crenshaw's landmark work on the compounded discrimination faced by black women in America, intersectional theorists argue that individuals are made up of several social identities - gender, race, caste, class and other social identities. ${ }^{108}$ These identities together determine the extent and nature of discrimination that people face. ${ }^{109}$

An understanding of discrimination thus requires an internalisation of the idea that there are several axes of identities under which an individual can face discrimination. The combinations of such axes are several, and indeterminate. This leads to a unique kind of complexity. Recognising this complexity, feminist theorists have emphasised lived experiences and contexts in determining whether or not discrimination exists, particularly of an intersectional kind.

As a result of this complexity of intersecting axes, legal systems can only account for the unique kind of discrimination faced by a person by understanding context and uncovering the identities which are interacting in a certain case to cause discrimination against an individual. In this case, then, vagueness is more suitable than precision as a regulatory frame.

The value of vagueness can be grasped by a case study that Crenshaw highlights in her work on intersectionality. In the American case of DeGraffeinreid $v$. General Motors Assembly Div., ${ }^{110}$ five black women sued General Motors for their employment policy that perpetuated discrimination against black women. In this case, the district court held in favour of the women's employersGeneral Motors. The judge held that while there existed a specific legislative remedy against sex-based discrimination that the women could avail, and a specific legal-remedy against race-based discrimination that they could also avail, there was no provision to combine the two specific remedies. An excerpt from the court's decision is as follows:

The plaintiffs are clearly entitled to a remedy if they have been discriminated against. However, they should not be allowed to combine statutory remedies to create a new 'super-remedy', that would give them relief beyond what the drafters of the relevant statutes intended. ${ }^{111}$

This case shows the problem with defining discrimination solely by specifying characteristics, rather than through using relatively vague expressions that cover the concept of discrimination. As the court was bound by the precise legal language of the legislature, they were not free to grant protection to the black women against the discriminatory policies of General Motors.

108. Kimberle Crenshaw, "Demarginalizing the Intersection of Race and Sex: A Black Feminist Critique of Antidiscrimination Doctrine, Feminist Theory and Antiracist Politics" (1989) U Chicago Legal F 139.

109. Ibid.

110. 413 F Supp 142 (Mo Dist Ct 1976) [Degraffenreid].

111. Ibid at 143 . 
The law on intersectional claims has fluctuated significantly since DeGraffeinreid. ${ }^{112}$ While some American courts have been receptive to intersectional claims, ${ }^{113}$ the problem still persists (albeit in new forms). Even where intersectional claims are allowed, courts have often resorted to what has been called the "sex-plus" approach. ${ }^{114}$ This approach sees people as composed of one identity plus another-a Black women is seen thus as a compound of two separate identities, instead of having the single, fused identity of a "Black woman". ${ }^{115}$ When employing this approach, courts end up mechanically adding the precise axes mentioned in a statute in their efforts to account for intersectional discrimination.

This sex-plus approach raises some concerns. First, marginalised groups do not always articulate (or indeed experience) discrimination as a mechanical addition of two distinct identities (here, sex and race) but rather as a single, distinctive experiential reality. ${ }^{116}$ These articulations find no place in sex-plus constructions. Second, the sex-plus approach also pushes us to ask how many identities can be added together in these hypothetical equations that courts are producing. Courts have briefly considered this question-leading them to restrict the number of axes that can be added together in intersectional claims. ${ }^{117}$ Therefore, the sex-plus construction is an inadequate interpretive tool. The complexities of intersectional discrimination cannot be captured through fixed mathematical constructions. As Catherine MacKinnon tells us, the intersectional method cannot truly be realised through "universal generalizations, classifications or abstractions in the clouds". 118 An intersectional method must be grounded in the lived experience of hierarchy, ${ }^{119}$ above all else.

How can legal systems, then, account for lived experiences in dealing with intersectional claims? It is important to recognise that the flawed sex-plus

112. See Catherine A MacKinnon, "Intersectionality as Method: A Note" (2013) 38:4 Signs 1019 at 1022. Mackinnon characterises the position of law on intersectional claims in the United States as oscillating between "truly getting" intersectionality and "truly missing it".

113. See Jeffries v Harris Community Action Ass'n, 615 F (2d) 1025 (5th Cir Ct App 1980) and Kimble v Wis Dept of Workforce Dev, 690 F Supp (2d) 765 (Wis Dist Ct 2010). The Equal Employment Opportunity Commission (EEOC) has also affirmed that Title VII of the Civil Rights Act of 1964 prohibits intersectional discrimination. See EEOC Compliance Manual (2006) 15-IV-C, online at https://www.eeoc.gov/laws/guidance/section-15-race-and-colordiscrimination\#IVC.

114. Under this approach, discrimination is limited to a combination of only two grounds. This was done in order to prevent the anti-discrimination legislation (Title VII) from being "splintered beyond use and recognition". See Judge v Marsh, 649 F Supp 770 at 779 (Dist Ct 1986) [Judge].

115. Mary Elizabeth Powell, "The Claims of Women of Color Under Title VII: the Interaction of Race and Gender" (1996) 26:2 Golden Gate UL Rev 413 at 421.

116. See Crenshaw, supra note 108 at 149. Crenshaw notes that sometimes Black women experience discrimination as Black women which is not merely the sum of race and sex discrimination. See also Mackinnon, supra note 112 at 1028 and Bradley Allan Areheart, "Intersectionality and Identity: Revisiting a Wrinkle in Title VII" (2006) 17:1 Geo Mason U Civ Rts LJ 199.

117. See Judge, supra note 114, where the Marsh Court established the "just pick two" rule, under which a Title VII plaintiff could claim only one "plus". This means that only two axes can be combined in an intersectional claim. See also Bradley Allan Areheart, supra note 116 at 221.

118. Mackinnon, supra note 112 at 1028.

119. Ibid. 
interpretive approach is, in part, a result of the linguistic priority accorded to precision over vagueness at the stage of law-making. When statutes list precise axes of discrimination, courts end up perfunctorily adding these axes together-leading to flawed interpretive approaches like the sex-plus construction. The use of precise statutory language proves to be a significant interpretive hurdle in the adjudication of intersectional claims. Therefore, while feminist reform has largely been (and should be) targeted at changing the interpretive approach taken by courts, the use of precise language at the stage of drafting anti-discrimination laws also merits serious questioning.

If we ask these questions, vagueness becomes increasingly relevant for discrimination law. Discrimination law theorists are confronted with the daunting task of defining discrimination-and in doing so, accounting for intersectionality. ${ }^{120}$ This debate has arisen, for instance, in the context of Article 15 of the Indian Constitution. Article 15 lists characteristics based on which discrimination can occur. ${ }^{121}$ By laying down a list of protected characteristics, the Constitution makers require all newer forms and types of discrimination to fit within or resemble one of the specified axes.

This precision comes at a cost. Indian courts, for instance, have been reluctant to grant that unequal treatment based on sexual orientation can be labelled discriminatory, as such treatment does not fit neatly within the ambit of "sex-based" discrimination that was precisely envisaged under Article $15 .{ }^{122}$ Further, Article 15 has been unsuccessful in dealing with claims of intersectional discrimination. ${ }^{123}$ As Shreya Atrey argues, intersectionality has had to "manoeuvre the roadblock of the constricted view of discrimination as based only on a single ground" incorporated within the precise wording of Article 15. ${ }^{124}$

120. See Atrey, supra note 89 and Shreya Atrey, Intersectional Discrimination (Oxford University Press, 2019).

121. The Constitution of India (2007 Rev Ed), Art 15.

122. See generally Suresh Kumar Koushal v Naz Foundation (2014), 1 SCC 1 (India) and Esha Shah, "Love and Sex in the Time of Section 377: Fantasising the 'Other', the 'Natural' and the "Normal"" (2013) 6:4 NUJS Law Review 613.

123. Shreya Atrey, "Through the Looking Glass of Intersectionality: Making Sense of Indian Discrimination Jurisprudence under Article 15" (2016) 16 The Equal Rights Review at 160-85. Under Article 15(1), discrimination cannot be made "against any citizen on grounds only of religion, race, caste, sex, place of birth or any of them". The "any of them" clause in this provision is vague. Scholars have argued that this expression helps make a case for allowing intersectional claims within the ambit of Article 15 (whereas the usage of the word "only" hinders such claims). See Gautam Bhatia, "Guest Post: Article 15(1) Through the Lens of Intersectionality-I" (10 June 2015), online at Indian Constitutional Law and Philosophy https://indconlawphil.wordpress.com/2015/06/10/904/ [perma.cc/H6SG-R87V] and Gautam Bhatia, "Guest Post: Article 15 through the lens of intersectionality-II" (14 June 2015), online at Indian Constitutional Law and Philosophy https://indconlawphil.wordpress.com/2015/06/ 14/guest-post-article-15-through-the-lens-of-intersectionality-ii/ [perma.cc/YL34-FYSU].

124. Shreya Atrey, supra note 123 at 160 . While Article 15 can perhaps be interpreted to accommodate for intersectional claims, the precision in the wording has harmed, rather than benefitted, this interpretive effort. 
Therefore, precision often has a damaging effect in laws relating to discrimination. Vagueness serves an important function in this domain. Tarunabh Khaitan, takes up the task of defining discrimination in the Anti-Discrimination and Equality Bill 2017, that was tabled before the Indian Parliament. ${ }^{125}$ Khaitan's definition incorporates vague predicates, as a necessary part of any definition of discrimination.

Khaitan defines the kind of characteristics that can be used as the basis for discriminatory action. These are "protected characteristics". Section 3 of the Bill first provides a list of protected characteristics and then, proceeds to include:

(ii) any other personal characteristic which,- - (a) is either outside a person's effective control, or constitutes a fundamental choice, or both; and (b) defines at least one group that suffers or is in danger of suffering widespread and substantial disadvantage, when compared with other groups defined by the same characteristic; or

(iii) a combination of any of the above. ${ }^{126}$

This definition is interesting as it does not merely list out axes for discrimination but goes further to allow for judicial discretion in cases by accommodating vague expressions such as "effective control", "fundamental choice" and "substantial disadvantage" in clause (ii). ${ }^{127}$ The use of vague expressions like these could be criticised for being too broad and flexible. However, it is only through a definition that is, to some extent vague, that intersectionality and social discrimination can be adequately dealt with.

Precise laws that seek to neatly define the axes on which discrimination occurs end up creating arbitrary and unjustifiable results as they cannot account for the complexity inherent in certain areas of human life. While in the context of care ethics, we dealt with the complexity that arises out of subjectivity, in intersectional issues we deal with the complexity that comes out of 'location'. ${ }^{128}$ Location, like subjectivity, has to be dealt with through vague predicates and expressions. Precision cannot effectively capture the layers and complexities of discrimination.

\section{Conclusion}

The preference for precision over vagueness is largely universal and finds backing in our concepts of law itself. By distinguishing clarity from precision, I have highlighted that while we must aspire for the former in the process of framing

125. Bill No 289, The Anti-Discrimination and Equality Bill, (India), Lok Sabha, 2017.

126. Ibid at s 3 .

127. In contrast, the Equality Bill 2020 tabled by the Centre for Law and Policy Research in India allows for a body called the Equality Commission to notify phenomena as "protected characteristics" as and when the need arises. See Centre for Law \& Policy Research, The Equality Bill 2020: Draft (17 January 2020), online at https://clpr.org.in/wp-content/uploads/2020/01/ Equality-Bill-2020-17-Jan-2020.pdf [perma.cc/T7Q5-GXCC].

128. See generally Emily Grabham et al, eds, Intersectionality and Beyond: Law, Power and the Politics of Location (Routledge-Cavendish, 2008). 
legal rules, the same cannot be said for the latter. This is because vagueness is inevitable in the structure of human language and in legal rules. Jurisprudential approaches that delineate a core of certainty from a penumbra of uncertainty in the language of legal rules are erroneous. They cannot accommodate for the fact that it is impossible to successfully draw a boundary line that separates the core from the penumbra, or the paradigm from the fringe. And so, we must live with vagueness. This inevitability of vagueness in the structure of language - and thus within legal rules - necessitates a proper understanding of vagueness's value.

Legal philosophers have theorised the value of vagueness in different ways. Diversifying our theoretical approaches helps us holistically understand vagueness's value. Considering this, I have suggested a perspectival shift to feminist philosophy to contextualise the value of vagueness. A feminist perspective can reveal the value-both intrinsic and instrumental-that vagueness possesses.

Drawing upon the feminist critique of the Cartesian dualism for its gendered nature, I submit that the precision/vagueness binary acts as an extension of this dualism. It replicates a gendered hierarchy. Precision endorses the model of rational and abstract knowledge-creation, while vagueness centralises embodied experience. Our legal cultures prioritise objectivity over subjectivity and leave little room for doubt when legal rules are drafted. This approach suppresses complexity. Vagueness is a unique linguistic tool that allows us to capture the lived experiences and contexts of legal subjects. Vagueness thus should be reclaimed by the project of feminist philosophy.

Vagueness not only possesses this intrinsic value, but also has certain instrumental benefits for feminist work in law. I have identified two theoreticaldoctrinal realms wherein vagueness is valuable. First, the doctrinal area of family law-understood here through the frame of feminist care ethics-reveals the complexity of relationality. There are ongoing efforts to precisely define legal criteria in family law. These approaches ignore the subjectivities inherent in relationality. The phenomenon of relationality cannot be dealt with effectively at the drafting stage through tools of abstraction. One needs to examine the particular relationship and its context to be able to judge its quality. Abstraction is thus redundant. Second, the doctrinal area of discrimination law-understood through the frame of intersectionality-reveals that discrimination based on social location is not best understood through precise legal language. The intersections of multiple axes can lead to an indefinite number and type of compounded social discrimination. The combination of these axes is fundamentally indeterminate.

It is my hope that this paper can initiate conversations and help conceptualise a feminist approach to the law-language question. I have shown that vagueness is a valuable linguistic tool for feminist legal work in certain specific areas. These areas of human life defy precision. They invite vagueness. In these areas, and perhaps many more, vagueness is of value. 